\title{
Qualitative assessment of chronic pain management in patients undergoing computed tomography-guided procedures
}

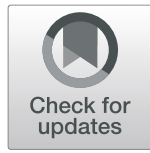

\author{
Ralph Jeffrey ${ }^{1}$, Roy Santosham', Gayathri Nagenthran ${ }^{2 *}$ (D, Bhawna Dev ${ }^{1}$, Rupesh Mandava $^{3}$, \\ Praveenkumar Vasanthraj ${ }^{1}$ and Siddharth Saravanan ${ }^{1}$
}

\begin{abstract}
Background: To study the qualitative efficacy and safety of percutaneous pain management under CT guidance. The success rate of medical management for chronic pain in long term is very less. This study aids in evaluating the clinical success rate in each CT-guided pain management procedure we have done.

Results: Among the 60 patients, 39 (65\%) were male patients and 21 (35\%) were female patients. We did 40 celiac plexus neurolysis (66.7\%), 13 radiofrequency ablations (21.6\%), 4 stellate ganglion neurolysis (6.7\%), and 3 trigeminal nerve neurolysis (5\%). The average pre-procedural pain score in all the procedures was 7 which was significantly reduced to 1 in $24 \mathrm{~h}$ and 1 and 3 months.

Conclusion: Percutaneous pain management under $C T$ guidance by virtue of its precise needle placement offers effective pain relief. It has a lower rate of complications, reduces the need for repeat procedures, and ultimately increases the quality of life.
\end{abstract}

Keywords: Pain management, CT guidance, Neurolysis

\section{Background}

Pain is defined as "an unpleasant sensory or emotional experience associated with actual or potential tissue damage or described in terms of such damage." It affects the quality of the patient's life by affecting their physical, psychological, and social aspects. The common causes of excruciating pain are cancerrelated, bone pathology, and neuropathic-related pain. Opioids are the mainstay of analgesics for chronically ill patients; however, they are not readily available in our country to common people; hence, percutaneous pain management is preferred. Initially, $\mathrm{C}$-arm fluoroscopy was used for facet and nerve root blocks using anatomical landmarks with a large amount of steroid and/or local anesthetics. Among the various imagingguided modalities like fluoroscopy, ultrasound (USG),

* Correspondence: g3nagikrish@gmail.com

${ }^{2}$ Medall Diagnostic Service Centre, Chennai, India

Full list of author information is available at the end of the article and computed tomography (CT) for percutaneous management of pain, CT-guided procedures have a lower rate of complications [1]. CT enhances anatomic resolution with a more precise needle tip positioning. Our study explains the efficacy of immediate pain relief in patients who have failed medical management. Percutaneous pain management can be of two types. They are "block" which is a temporary process by injecting steroids or long-acting anesthetics and "neurolysis" which is a near-permanent process of injecting alcohol.

\section{Methods \\ Patients}

This is a prospective study done from July 2010 to August 2013 at our institution. Institutional ethics committee and informed written consent from patients were obtained. Sixty patients have an age ranging from 4 to 80 years (mean 43.4 years). The commonest age group in 


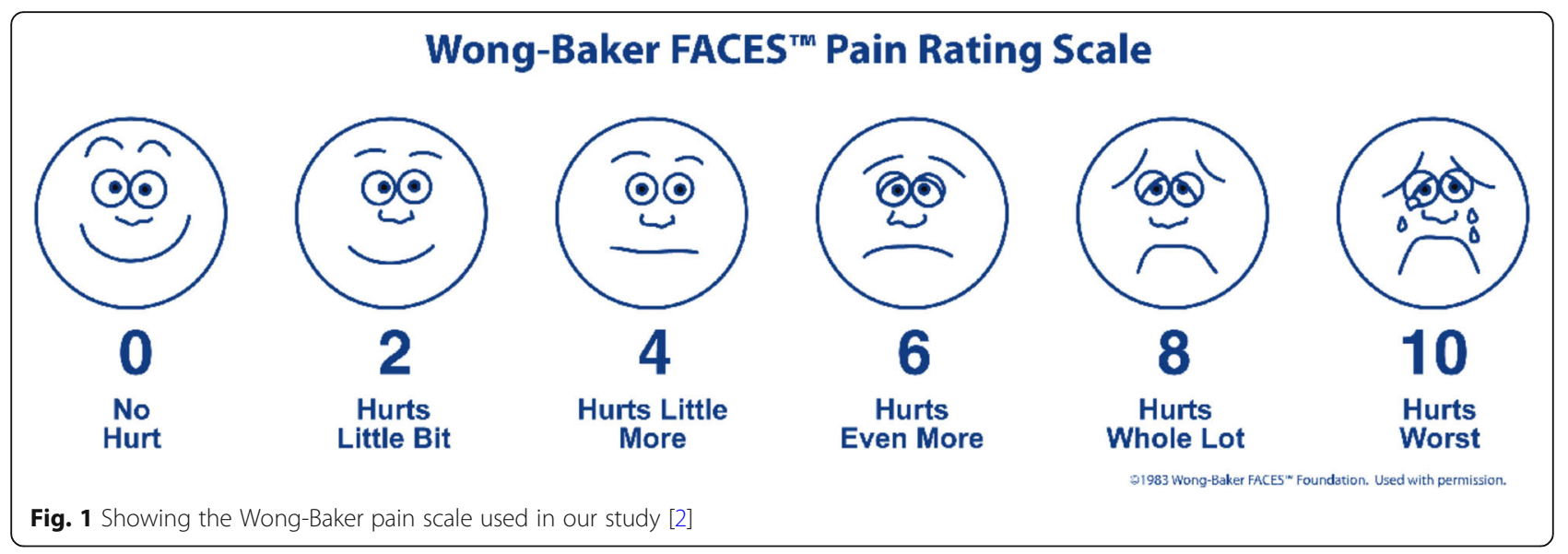

our study is the 6th decade followed by the 3rd and 4th decades. Among the 60 patients selected in our study, 39 (65\%) were males and 21 (35\%) were females. We included patients who had a history of failed medical management, and they were referred to the Department of Interventional Radiology. We excluded patients with deranged coagulation profile and patients benefiting from medical management.

\section{Pre-treatment patient assessment}

The pre-procedural workup included clinical evaluation, coagulation profile, liver function test, renal function

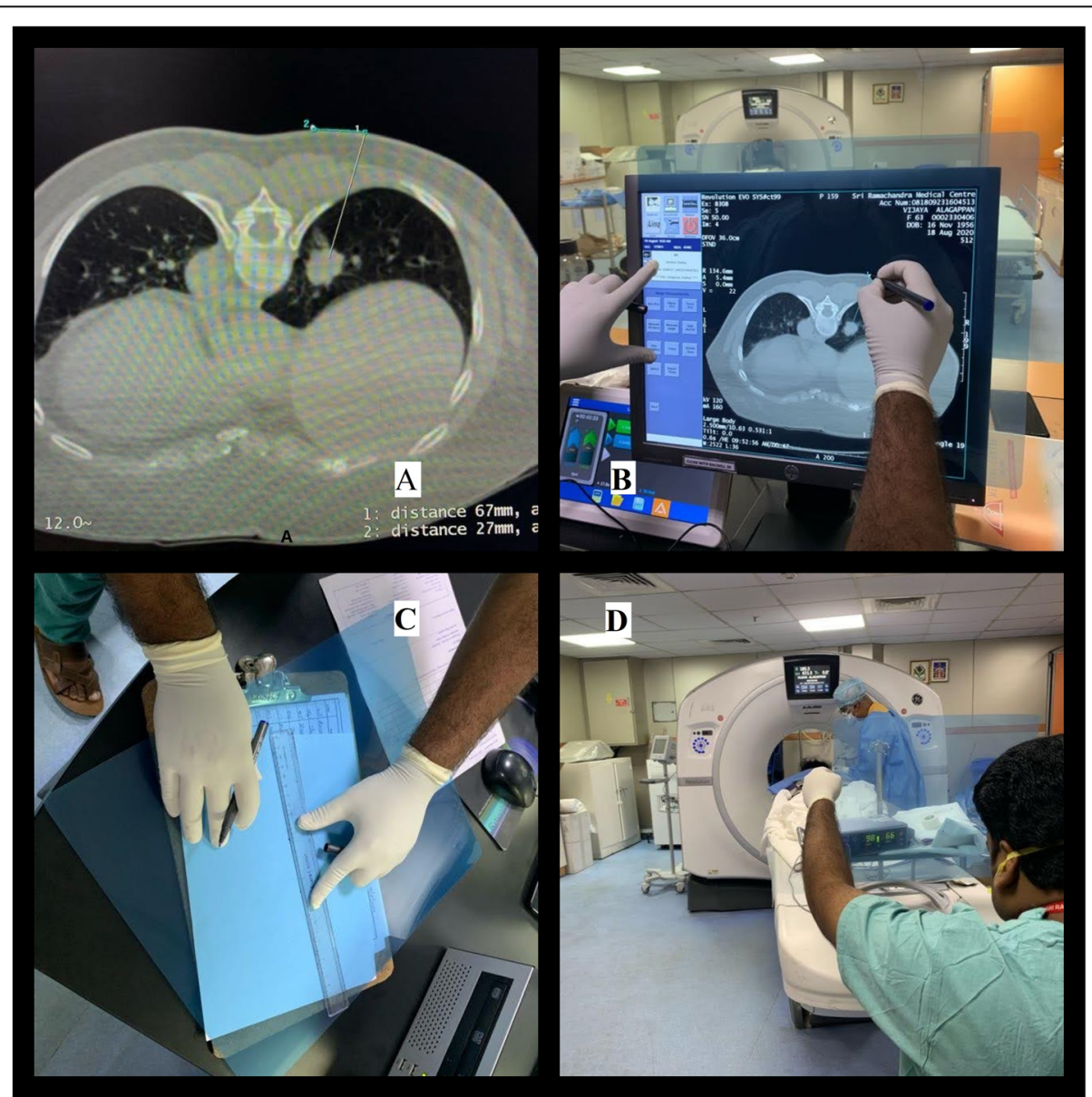

Fig. 2 a Distance between the point of entry and target region is measured. $\mathbf{b}$ The point of entry and the target region are marked in a transparent sheet against the monitor. c Draw a line joining these two points. $\mathbf{d}$ An assistant holding the transparent sheet from the foot end 


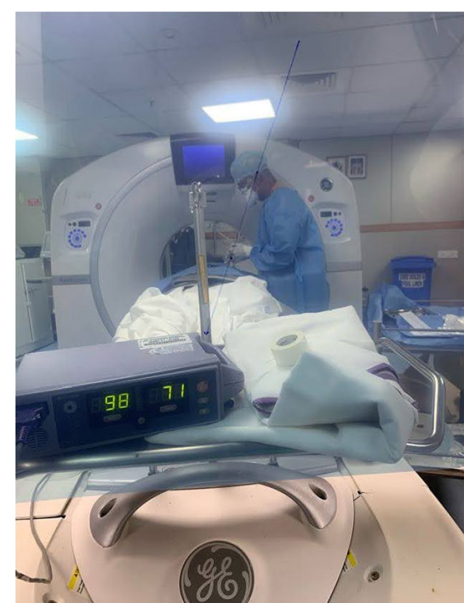

Fig. 3 A view through the transparent sheet. The operator is inserting the needle along the orbital angle of incidence guided by an assistant by seeing through the sheet

test, HIV and HbsAg, and thorough reading of imaging studies. The pain score evaluation was done by WongBaker's scale (Fig. 1). It is a self-evaluating scale showing a series of faces ranging from a happy face at 0, "no hurt," to a crying face at 10 , "worst pain possible." The patient must choose the face that best describes how they are feeling at that time.

\section{CT-guided needle placement}

The patient is placed on the table depending on the approach. The CT images are acquired for the patient and the slice showing the appropriate target (lesion) for needle placement is chosen. The point of entry is chosen on the image. The table with the patient is moved to the chosen slice position, and radio-opaque fiducial soaked in contrast is placed at the point of entry. Check slice is then acquired. The angle of incidence of the needle is ascertained (Fig. 2a), the point of entry and target region are marked (Fig. 2b), and the line connecting those two points is traced on a transparent film (Fig. 2c). The needle while being inserted by the operator is seen through the transparent film held by an assistant from the foot end (Fig. 2d), who guides the orbital angle of incidence (Fig. 3). After sterile precautions and under local anesthesia, the needle is inserted to the desired depth, and a check scan is performed.

\section{Celiac plexus neurolysis}

The celiac plexus is a pair of dense networks of nerves which is located in the retroperitoneum near the origins of the celiac and superior mesenteric arteries. It comprises pre-ganglionic sympathetic efferent nerve fibers derived from the greater splanchnic (T5-T9), lesser splanchnic (T10-T11), and least splanchnic (T12) nerves; preganglionic parasympathetic efferent fibers from the posterior trunk of the vagus nerve; and the visceral afferent fibers that carry nociceptive stimuli from the upper abdominal viscera (Fig. 4). The left celiac plexus is more caudal in relation to the right celiac plexus. The right plexus is difficult to visualize due to its location between IVC and the right diaphragmatic crus [3]. Common indications

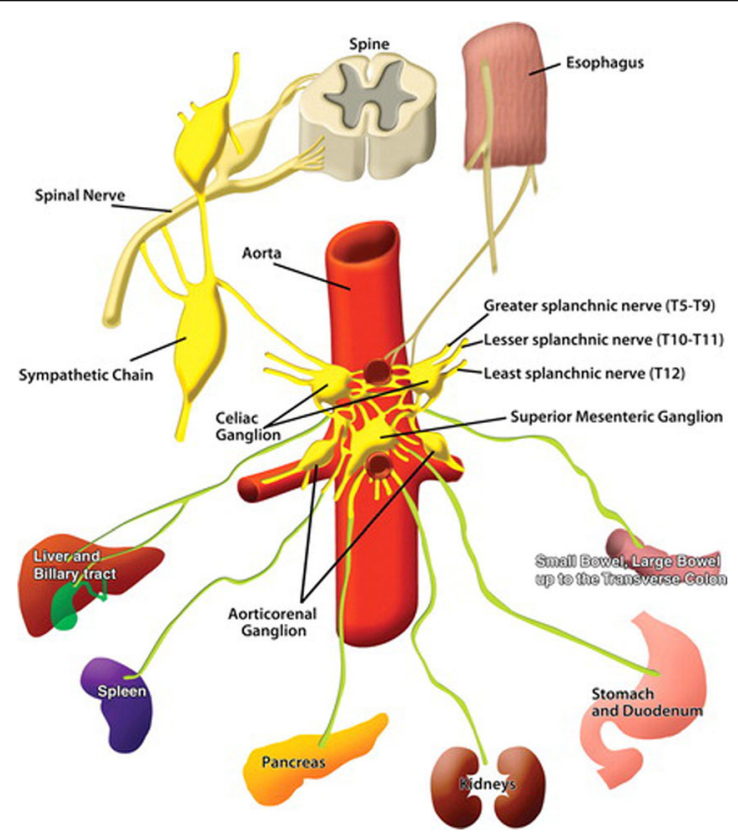

Fig. 4 Schematic diagram showing the celiac plexus anatomy [3] 


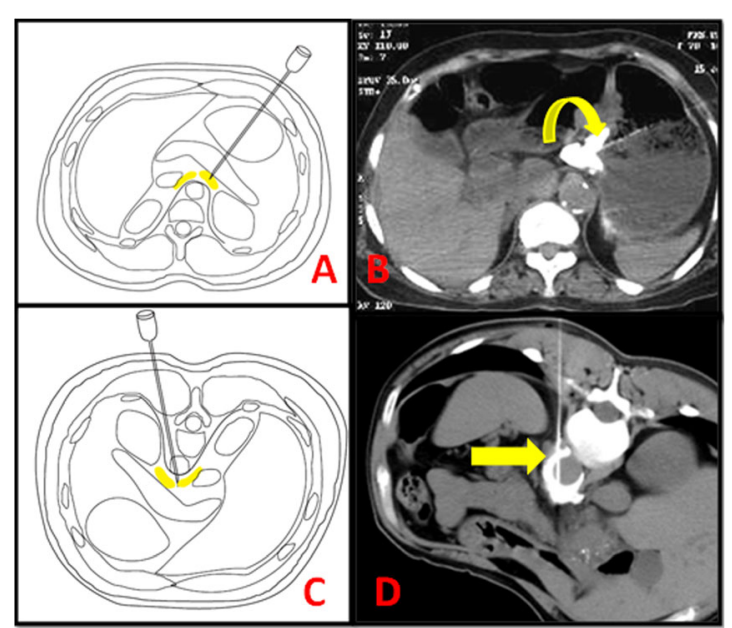

Fig. 5 Celiac plexus block. Schematic (a) and axial CT section post-procedural free flow of contrast (b) of transgastric approach. Schematic (c) and CT section post-procedural free flow of contrast (d) of transaortic approach

are tumors of the pancreas, stomach, duodenum, and liver and chronic pancreatitis. A 14-ml mixture of 8 $\mathrm{ml}$ of $80 \%$ ethanol, $2 \mathrm{ml}$ of $2 \%$ lignocaine, $2 \mathrm{ml}$ of $0.5 \%$ bupivacaine, and $2 \mathrm{ml}$ of iohexol contrast medium is injected (Figs. 5, 6, and 7). Pain, diarrhea, and hypotension are expected to occur in this procedure. Various approaches are mentioned in Table 1.

\section{Retrocrural neurolysis}

The retrocrural space is a triangular space located in the inferior most aspect of the posteromedial thoracic cavity. It is bounded by the diaphragmatic crura anterolaterally and by the distal thoracic and proximal lumbar vertebral body posteriorly. Retrocrural neurolysis (RN) targets the thoracic splanchnic nerves that carry pain signals from the celiac plexus to the spinal cord in the space posterior to the diaphragmatic crura [5]. The advantage of $\mathrm{RN}$ over celiac plexus neurolysis $(\mathrm{CPN})$ is that the retrocrural space is more superficial and less number of structures is traversed (Fig. 8). The complication rates are very low with improved pain relief.

\section{Stellate ganglion neurolysis}

The stellate ganglion (cervicothoracic ganglion) is a sympathetic ganglion formed by the fusion of the inferior cervical ganglion and the first thoracic ganglion. It is located at the C7-T1 level anterior to the neck of the 1st rib, lateral to the longus colli muscle, and posterior to the vertebral artery (Fig. 9) [4]. Various approaches done

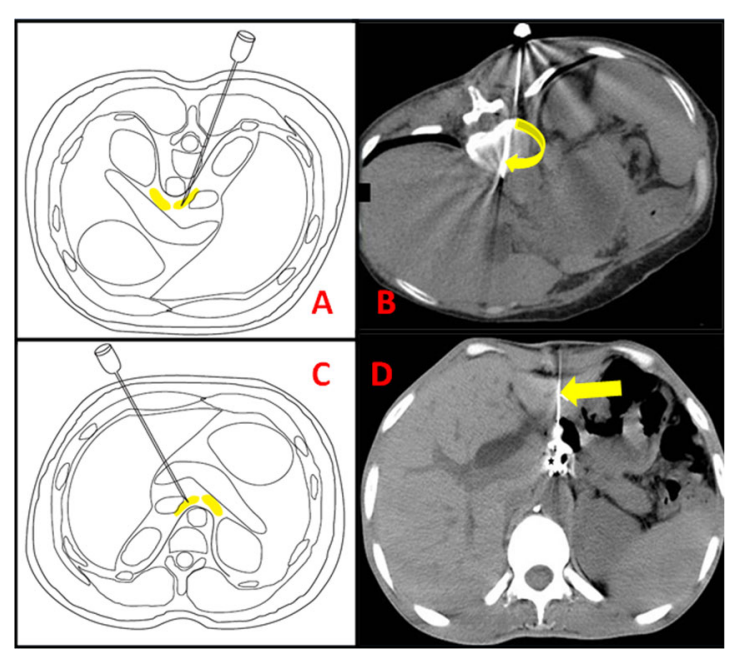

Fig. 6 Celiac plexus block. Schematic (a) and axial CT section (b) post-procedural needle tip (curved arrow) of transdiscal approach. Schematic (c) and $C T$ section post-procedural free flow of contrast (d) of anterior transhepatic approach 


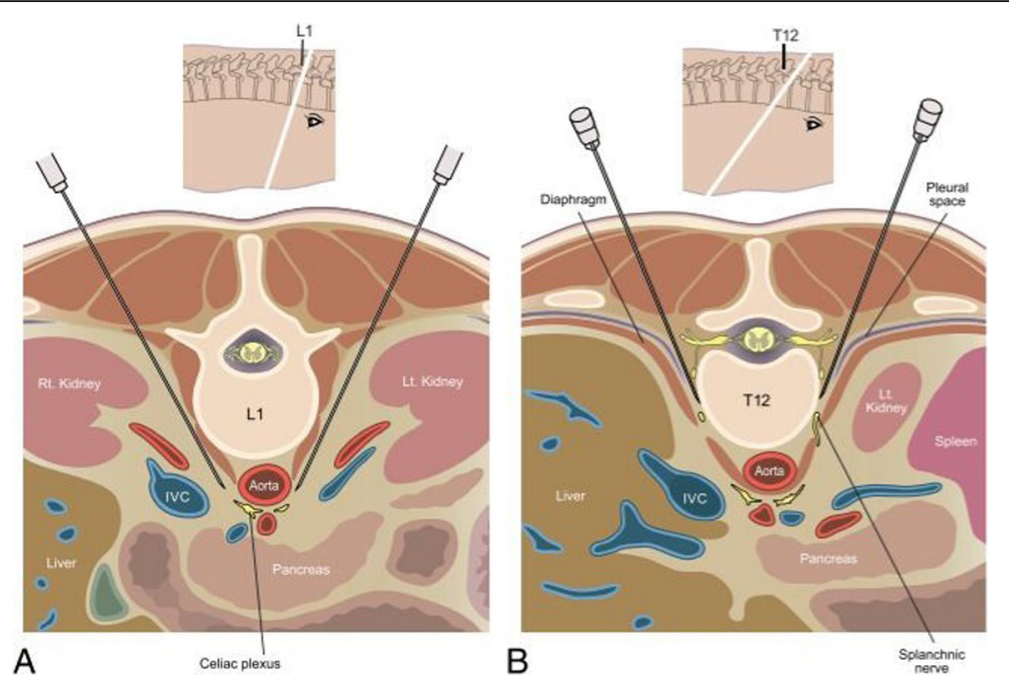

Fig. 7 Schematic diagram showing the tip of needle placement in the celiac plexus (a) and retrocrural (b) neurolysis [4]

in our study are shown in Table 2 . This procedure is indicated in pain syndromes such as complex regional pain syndromes, phantom limb pain, reflex sympathetic dystrophy, herpes zoster, hyperhidrosis, and pain of the head and neck and arterial vascular insufficiency (Reynaud syndrome, scleroderma, vasospasm, obliterative vascular diseases, emboli, and trauma). One of the common complications encountered is injury to the adjacent vascular structures (vertebral artery, carotid artery, and internal jugular vein). In pneumothorax, intravascular/ intrathecal injection of local anesthetic can result in arrhythmia, seizure, and cardiovascular collapse. A mixture of $2 \mathrm{ml}$ of $80 \%$ ethanol mixed with $2 \mathrm{ml}$ of bupivacaine and $1 \mathrm{ml}$ of contrast is prepared. Of the abovementioned mixture, $1.5 \mathrm{ml}$ is taken and injected (Figs. 10, 11, and 12) into the target site.

\section{Trigeminal neurolysis}

The trigeminal ganglion is contained within the Meckel's cavity posterolateral to the cavernous sinus. It has three divisions: ophthalmic (V1), maxillary (V2), and mandibular (V3). Motor root fibers are distributed to the mandibular division which exits via the foramen ovale (Fig. 14). The ophthalmic nerve and maxillary nerve travel laterally to the cavernous sinus exiting via the superior orbital fissure and foramen rotundum, respectively [7].

Table 1 Shows different approaches and no. of attempts we did in our study for the celiac plexus

\begin{tabular}{ll}
\hline Approaches & No. of attempts \\
\hline Anterior transhepatic & 3 \\
Posterior transdiscal & 1 \\
Posterior transaortic & 1 \\
\hline
\end{tabular}

The main indication for the procedure is the trigeminal neuralgia. Trigeminal nerve block was performed with the patient in the supine position with the head placed in reverse occipitomental position (chin up and neck extended), turned $30^{\circ}$ to the opposite side. The foramen ovale is identified under CT guidance. CT-guided needle placement is carried out, and a 22-G spinal needle is advanced to reach the foramen of the ovale. A $1.5-\mathrm{ml} \mathrm{mix}$ ture containing $1 \mathrm{ml}$ of $80 \%$ alcohol and $0.5 \mathrm{ml}$ lignocaine with contrast is injected into the foramen ovale (Fig. 15). Expected complications are abolition of corneal reflexes causing exposure keratitis and dryness of eyes and arachnoiditis/meningitis (if accidental injection of alcohol into the CSF space).

\section{Radiofrequency ablation}

Osteiodosteoma (OO) is a benign painful condition affecting the young population. Surgery has been the usual method of treating these patients. Resection of the lesion, with curettage of the perifocal bone, effected a prompt clinical cure in these cases. Radiofrequency ablation (RFA) is a simple, minimally invasive, safe, and highly effective technique for the treatment of OO [8]. CT-guided RFA of osteoid osteoma was done under general anesthesia. Grounding

Table 2 Different approaches and no. of attempts we did in our study for the stellate ganglion

\begin{tabular}{ll}
\hline Approach & $\begin{array}{l}\text { No. of } \\
\text { attempts }\end{array}$ \\
\hline Classic & 2 \\
Posterolateral & 1 \\
$\begin{array}{l}\text { Hydrodissection (to separate the carotid and jugular } \\
\text { veins) (Fig. 13) }\end{array}$ & 1 \\
\hline
\end{tabular}




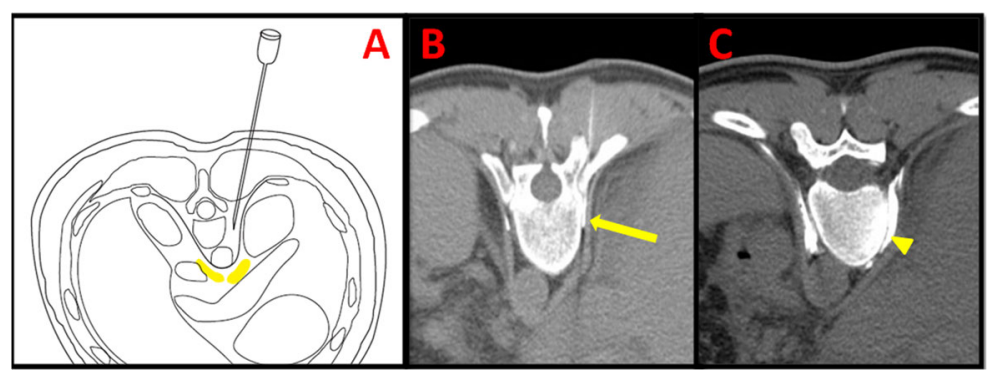

Fig. 8 Retrocrural neurolysis. Schematic (a) and axial CT section of the pre-procedure (b) with needle tip in the left retrocrural space and postprocedural free flow of contrast (c) in the retrocrural space

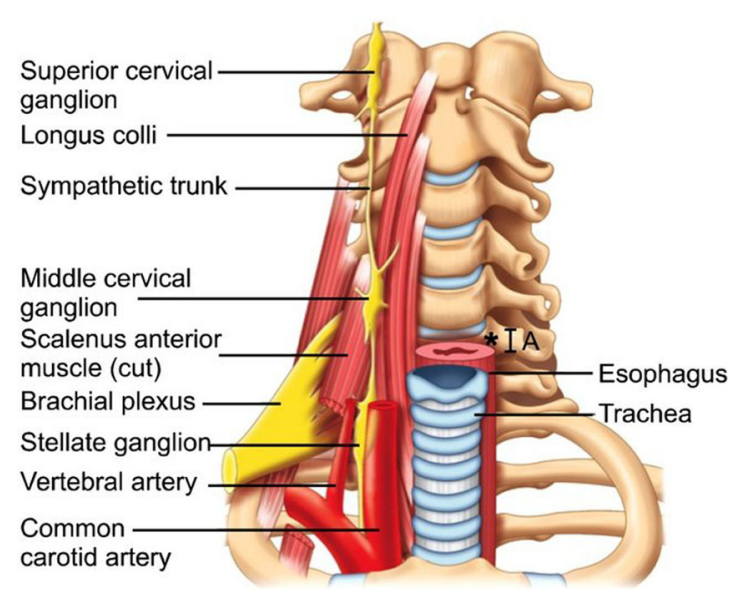

Fig. 9 Schematic diagram of the stellate ganglion [14]

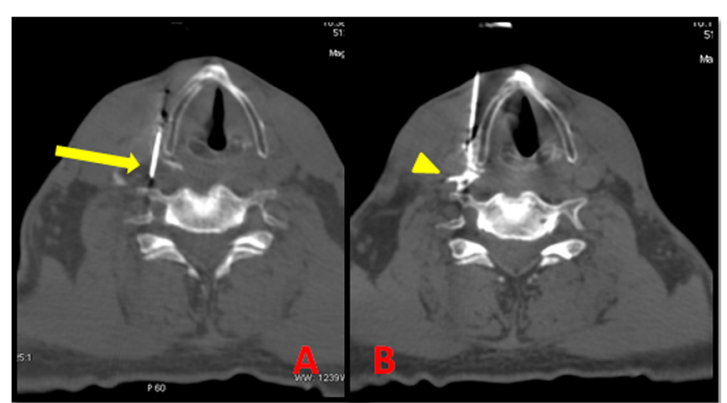

Fig. 10 Anterior approach in stellate ganglion block for Pancoast tumor. Axial CT section (a) of the pre-procedure showing the needle tip in the stellate ganglion and post-procedure (b) free flow of contrast (arrowhead) in the stellate ganglion

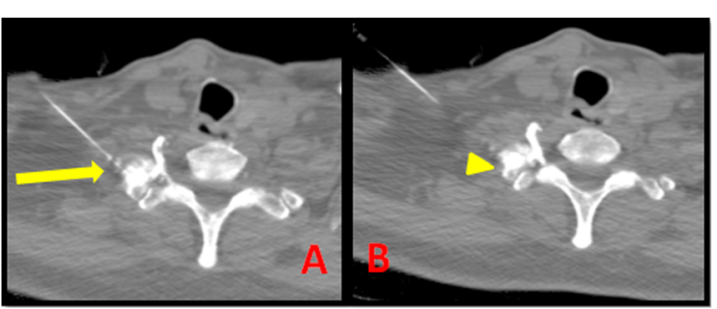

Fig. 11 Antero-lateral approach in stellate ganglion block. Axial CT section (a) of the pre-procedure showing the needle tip in the stellate ganglion and post-procedure (b) free flow of contrast (arrowhead) in the stellate ganglion 


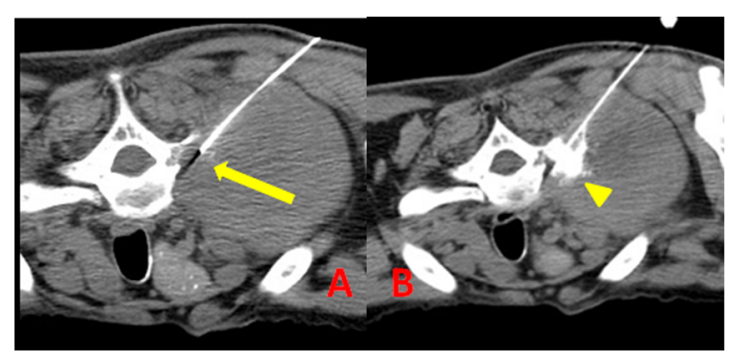

Fig. 12 Postero-lateral approach in stellate ganglion neurolysis. Axial CT section (a) of the pre-procedure showing the needle tip in the stellate ganglion and post-procedure (b) free flow of contrast (arrowhead) in the stellate ganglion

pads are put in place away from the point of entry. The nidus is accessed with a bone biopsy trephine needle (Murphy's 11-G needle). The stylet of the needle is exchanged for a K-wire. Then, the cannula over the K-wire is removed and is exchanged for an insulated cannula. The $\mathrm{K}$-wire is then removed and exchanged for an RF electrode (Starburst SD, AngioDynamics) which is passed through the insulated cannula and is placed within the nidus (Fig. 16). The RF electrode is then connected to the RF generator, and thermal heating is applied at a temperature of $90{ }^{\circ} \mathrm{C}$ for $7-8 \mathrm{~min}$. RFA is the preferred treatment for extraspinal osteoid osteoma because of the advantages such as quick recovery, no hospitalization, and free from complications [9].

\section{Aftercare and follow-up}

Patients were re-evaluated at regular intervals $(24 \mathrm{~h}, 1$ and 3 months) over a phone call. Each time, they were asked to mention their Wong-Baker pain score scale.

\section{Results}

The most common procedure in our study was celiac plexus neurolysis in 40 (66.7\%), 13 cases underwent radiofrequency ablation (21.6\%), 4 cases stellate ganglion neurolysis $(6.7 \%)$, and 3 cases trigeminal nerve neurolysis $(5 \%)$.

The maximum pre-procedural pain score in all the procedures was 9 in a patient with chronic pancreatitis which subsided to a pain score of 0 after $24 \mathrm{~h}$ post-celiac plexus neurolysis. The minimum pre-procedural pain score was 6 in patients diagnosed with trigeminal neuralgia, and the pain reduced to 0 after $24 \mathrm{~h}$ of trigeminal neurolysis.

The mean pain score of the pre-procedure, $24 \mathrm{~h}$, and 1 and 3 months post-procedure obtained after each percutaneous CT-guided neurolysis is outlined in Table 3.

Fifty-four patients out of 60 (90\%) showed a total disappearance of their pain over 3 months post-procedure. Five patients out of $60(8.4 \%)$ showed a marked reduction in their pain scores.

One patient out of $60(1.6 \%)$ had not responded well regarding the pain score. This patient (62 years, male) returned to the department within 2 days after $\mathrm{TN}$, as he had no relief of pain after 1 day. Hence, a repeat procedure was attempted. Since there was CSF aspirate while attempting the procedure, the repeat procedure was abandoned.

A graph showing the mean pain score before and after $24 \mathrm{~h}$ and 1 and 3 months post-procedure in each CTguided pain management. ( $\mathrm{RN}$, retrocrural neurolysis; $\mathrm{CPN}$, celiac plexus neurolysis; SGN, stellate ganglion neurolysis; TN, trigeminal neurolysis; RFA, radiofrequency ablation)

\section{Discussion}

Management of pain is the most important issue to be addressed by the health care system to improve the quality of individual life. Initial treatment for pain is oral non-steroidal anti-inflammatory drugs (NSAIDs), corticosteroids, and opioids. Despite increased attention to the assessment and treatment of pain, many barriers still

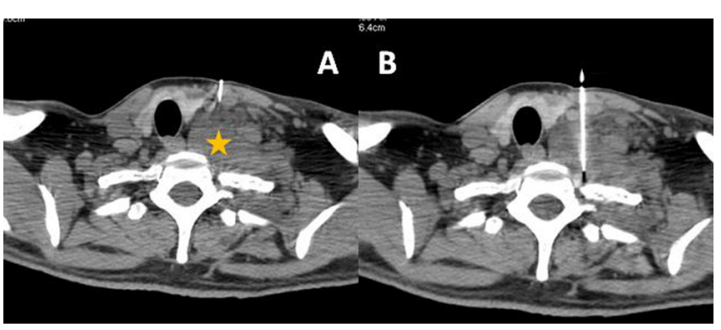

Fig. 13 Hydrodissection approach for stellate ganglion neurolysis. Axial CT section showing the a injection of saline (star). b Needle tip passing through the saline into the stellate ganglion 


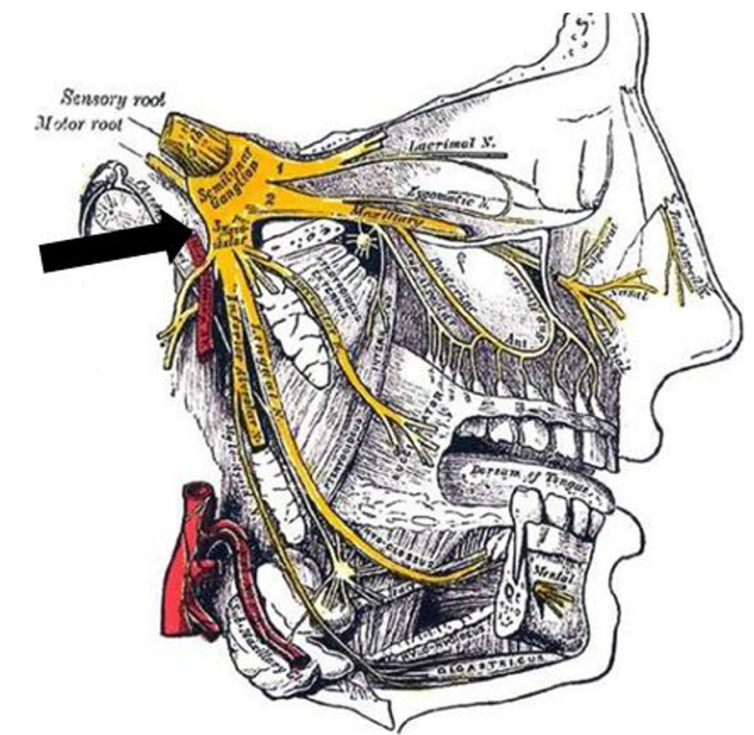

Fig. 14 Divisions of the trigeminal nerve. The arrow shows the mandibular division exiting via the foramen ovale [6]

exist causing patient dissatisfaction. Historically, fluoroscopy-guided nerve root block was performed by palpating anatomical landmarks. However, important structures such as the vessels and visceral organs along the path of the needle are not visualized resulting in serious mortality and morbidity to the patients. CT offers a better spatial resolution and greater cross-sectional anatomy. CT in contrary to fluoroscopy guidance allows precise needle placement with a minimal complication rate.

The drugs we used are bupivacaine, lignocaine, and $80 \%$ ethanol. Anesthetics (bupivacaine and lignocaine) act by blocking conduction in nociceptive fibers because of their effects on sodium channels, decreasing sensations arising from inflamed tissue. Ethanol acts by destroying the surrounding structure.

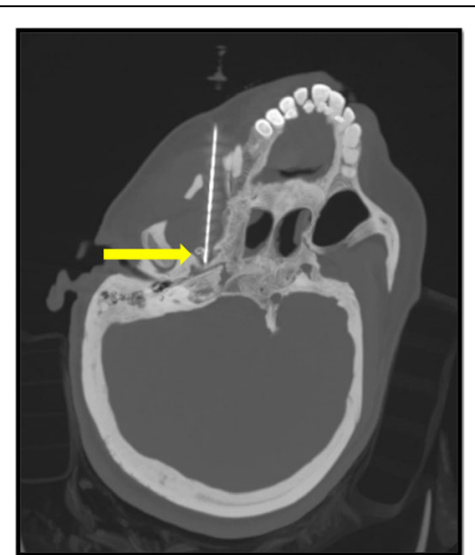

Fig. 15 Axial CT section of the skull base with the needle tip at the foramen ovale (straight arrow)

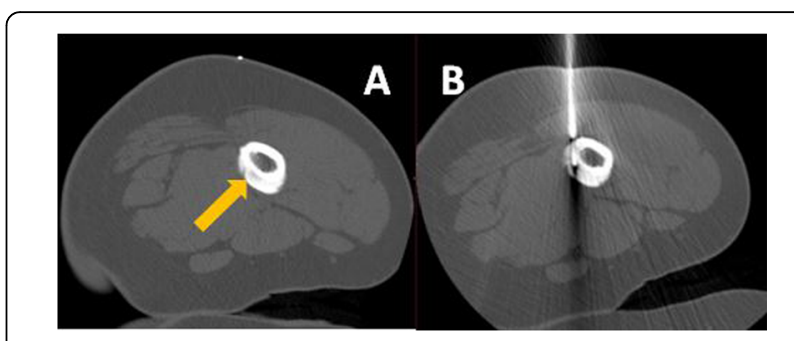

Fig. 16 Radiofrequency ablation. Axial section of right femur shows $\mathbf{a}$ the nidus with a thickened cortex. $\mathbf{b}$ RF electrode tip noted within the lesion

We considered the complete or marked relief of patient's symptoms without the use of oral medications or physical therapy within the first 3 months after the procedure as a "clinical success."

Retrocrural neurolysis of the splanchnic nerve gave good results than celiac plexus neurolysis. Later in 2012, Süleyman et al.'s study concluded that splanchnic nerve blockade can be an alternative to coeliac plexus block in patients with advanced body and tail located pancreatic cancer [10]. In all these patients $(n=33)$ pain score remained 0 for 3 months. The clinical success rate was $100 \%$ with RN when compared to $85 \%$ of CPN.

Two out of 3 patients $(66.7 \%)$ had a significant reduction of pain following TN. This was similar to the study done by Han et al., stating that trigeminal nerve block with a high concentration of lidocaine $(10 \%)$ is capable of achieving an intermediate period of pain relief, particularly in patients with lower pain and shorter duration of pain prior to the procedure [11]. One out of 3 patients $(33.3 \%)$ had a failed procedure. Three patients encountered exposure keratitis which was treated with topical corticosteroids and eye patch. The clinical success rate was only $66.7 \%$ for $\mathrm{TN}$.

Radiofrequency ablation of $\mathrm{OO}$ was the second most common procedure in our study where 13 patients presented with severe pain at different locations (femur, 7; tibia, 4; lumbar spine, 1) at night. All 13 patients had a pain score of 0 immediately after the procedure and were completely pain-free even at 3 months after the procedure. Hence, the clinical success rate was $100 \%$.

Stellate ganglion neurolysis was done for pain associated with Pancoast tumor. A clinical success rate of $75 \%$ was found in SN. Hydrodissection was done in one of our patients to widen the space between the carotid artery and the internal jugular vein for easy approachability of the stellate ganglion.

The limitation of our study is that the number of patients for neurolysis is less than that for retrocrural neurolysis. In our study, we neither did a comparative study with ultrasound guidance nor a blind method; however, we depended on the clinical response of the patients as a 
Table 3 The mean pain score before and after $24 \mathrm{~h}$ and 1 and 3 months post-procedure in each CT-guided pain management

\begin{tabular}{lllll}
\hline Procedure & $\begin{array}{l}\text { Pre-procedure mean } \\
\text { pain score }\end{array}$ & $\begin{array}{l}\text { Post-procedure (24 h) mean } \\
\text { pain score }\end{array}$ & $\begin{array}{l}\text { Post-procedure (1 month) } \\
\text { mean pain score }\end{array}$ & $\begin{array}{l}\text { Post-procedure (3 months) } \\
\text { mean pain score }\end{array}$ \\
\hline $\begin{array}{l}\text { Retrocrural } \\
\text { neurolysis }\end{array}$ & 7 & 0 & 0 & 0 \\
$\begin{array}{l}\text { Coeliac plexus } \\
\text { neurolysis }\end{array}$ & 8 & 0 & 0 & 2 \\
$\begin{array}{l}\text { Stellate ganglion } \\
\text { neurolysis }\end{array}$ & 7 & 0 & 1 & 0 \\
$\begin{array}{l}\text { Trigeminal } \\
\text { neurolysis }\end{array}$ & 7 & 0 & 2 & 1 \\
$\begin{array}{l}\text { Radiofrequency } \\
\text { ablation }\end{array}$ & 8 & 0 & 0 & 0 \\
\hline
\end{tabular}

qualitative indicator of effectiveness. One theoretical disadvantage of $\mathrm{CT}$ guidance is the increased radiation dose involved in the procedure. By using low-dose protocols and limiting the number of slices acquired, radiation dose could be significantly reduced, as demonstrated by Slomczykowski et al. for pedicle screw insertion [13].

\section{Conclusion}

Percutaneous pain management under CT guidance by virtue of its precise needle placement offers effective pain relief. It has a lower rate of complications, reduces the need for repeat procedure, and increases the quality of life.

\section{Abbreviations}

USG: Ultrasound; CT: Computed tomography; RN: Retrocrural neurolysis; CPN: Celiac plexus neurolysis; TN: Trigeminal neurolysis; NSAID: Non-steroidal anti-inflammatory drugs; RFA: Radiofrequency ablation; OO: Osteoid osteoma

\section{Acknowledgements}

Not applicable

\section{Authors' contributions}

$\mathrm{RJ}$ and RS designed the concept. GN, BD, and RM analyzed and interpreted the patient data regarding the patient selection and did the literature search. $B D, R J, R S, R M, P K$, and SS performed the CT-guided procedure. GN played is a major contributor in writing the manuscript. The authors read and approved the final manuscript.

\section{Funding}

This study had no funding from any resource.

\section{Availability of data and materials}

The datasets used and/or analyzed during the current study are available from the corresponding author on reasonable request.

\section{Ethics approval and consent to participate}

This study was approved by the Research Ethics Committee of the Faculty of Medicine at Sri Ramachandra University on 23 August 2013, reference number of approval: CSP-med/16/aug/24/24. All patients included in this study gave written informed consent to participate in this research. If the patient was less than 16 years old or unconscious at the time of the study, written informed consent for their participation was given by their parent or legal guardian.

\section{Consent for publication}

All patients included in this research gave written informed consent to publish the data contained within this study. If the patient was less than 16 years old, deceased, or unconscious when consent for publication was requested, written informed consent for the publication of this data was given by their parent or legal guardian.

\section{Competing interests}

The authors declare that they have no competing interests.

\section{Author details}

${ }^{1}$ Sri Ramachandra institute of Higher education and Research Centre, Chennai, India. ${ }^{2}$ Medall Diagnostic Service Centre, Chennai, India. ${ }^{3}$ Department of Radiology, Great Eastern Medical School and Hospital, Srikakulam, Andhra Pradesh, India.

Received: 15 May 2020 Accepted: 14 December 2020

Published online: 14 January 2021

\section{References}

1. Silbergleit R, Mehta BA, Sanders WP et al (2001) Imaging-guided injection techniques with fluoroscopy and $C T$ for spinal pain management. Radiographics 21(4):927-939 discussion 940-2

2. Savino F, Vagliano L, Ceratto S et al (2013) Pain assessment in children undergoing venipuncture: the Wong-baker faces scale versus skin conductance fluctuations. Peer J 1:e37 https://doi.org/10.7717/peerj.37

3. Kambadakone A, Thabet A, Gervais D et al (2011) CT-guided celiac plexus neurolysis: a review of anatomy, indications, technique, and tips for successful treatment. Radio Graphics 31:No. 6

4. Kamdar MM, Edwards DA, Thabet AM et al (2015) A novel modified retrocrural approach for celiac plexus block: the single-needle retroaortic technique. Reg Anesth Pain Med 40:610-615

5. Restrepo CS, Eraso A, Ocazionez D et al (2008) The diaphragmatic crura and retrocrural space: normal imaging appearance, variants, and pathologic conditions. RadioGraphics 28(5):1289-1305 https://doi.org/10.1148/rg. 285075187

6. Trigeminal Neuralgia (2019) Physiopedia Retrieved 19:17, August 14, 2020 from https://www.physio-pedia.com/index.php?title=Trigeminal_ Neuralgia\&oldid $=222844$

7. Lee JH, Cheng KL, Choi YJ et al (2017) High-resolution imaging of neural anatomy and pathology of the neck. Korean J Radiol 18(1):180-193 https:// doi.org/10.3348/kjr.2017.18.1.180

8. Kamel HAM, Toland J (2001) Trigeminal nerve anatomy. Am J Roentgenol 176(1):247-251

9. Woertler K, Vestring T (2001) Boettner F et al. Osteoid osteoma: CT-guided percutaneous radiofrequency ablation and follow-up in 47 patients. J VascInterv Radiol 12(6):717-722

10. Rosenthal DI, Hornicek FJ (1998) Wolfe MW et al. Percutaneous radiofrequency coagulation of osteoid osteoma compared with operative treatment. J Bone Joint Surg Am 80(6):815-821

11. N. Süleyman Özyalçın, Gül Köknel Talu, Hakanamlıca et al. Efficacy of coeliac plexus and splanchnic nerve blockades in body and tail located pancreatic cancer pain. https://doi.org/10.1016/j.ejpain.2004.01.00

12. Han KR, Kim C, Chae YJ et al (2008) Efficacy and safety of high concentration lidocaine for trigeminal nerve block in patients with trigeminal neuralgia. Int J Clin Pract 62(2):248-254 
13. Slomczykowski M, Roberto M, Schneeberger P et al (1999) Radiation dose for pedicle screw insertion. Fluoroscopic method versus computer-assisted surgery. Spine 24:975-982 https://doi.org/10.1097/00007632-19990515000009

14. Soneji N, Peng PWH (2013) Ultrasound-guided pain interventions - a review of techniques for peripheral nerves. Kor J Pain 26(2):111 https://doi.org/10. 3344/kjp.2013.26.2.111

\section{Publisher's Note}

Springer Nature remains neutral with regard to jurisdictional claims in published maps and institutional affiliations.

Submit your manuscript to a SpringerOpen ${ }^{\mathcal{O}}$ journal and benefit from:

- Convenient online submission

- Rigorous peer review

- Open access: articles freely available online

High visibility within the field

- Retaining the copyright to your article

Submit your next manuscript at $\boldsymbol{\nabla}$ springeropen.com 